\title{
Synovial and serum levels of osteocalcin, osteoprotegerin and $\beta$-crosslaps in patients with calcium pyrophosphate deposition disease
}

\author{
Paulina Vele ${ }^{1}$, Ciprian N. Silaghi², Laura O. Damian ${ }^{3}$, Siao-Pin Simon ${ }^{1,3}$, \\ Alexandra M. Craciun'2, Simona Rednic ${ }^{1,3}$ \\ ${ }^{1}$ Rheumatology Department, "Iuliu Hatieganu" University of Medicine and Pharmacy, \\ Cluj-Napoca, Romania \\ ${ }^{2}$ Medical Biochemistry Department, "luliu Hatieganu" University of Medicine and Pharmacy, \\ Cluj-Napoca, Romania \\ ${ }^{3}$ Rheumatology, Emergency County Teaching Hospital, Cluj-Napoca, Romania
}

\begin{abstract}
Background. Calcium pyrophosphate deposition disease is defined by deposition of calcium pyrophosphate crystals in hyaline cartilage, fibrocartilage and soft tissues. The study of bone markers is of great interest in different types of arthritis. In patients with calcium pyrophosphate deposition disease, bone turnover markers may yield additional information from many perspectives.

Objectives. To measure synovial and serum levels of osteocalcin, osteoprotegerin and $\beta$-CrossLaps in patients with calcium pyrophosphate deposition disease.

Material and methods. In this pilot, prospective study were enrolled eight patients with calcium pyrophosphate deposition disease. Osteocalcin, osteoprotegerin and $\beta$-CrossLaps were measured in serum and in the synovial fluid using ELISA kits.

Results. Synovial fluid osteocalcin was significantly lower comparative with serum osteocalcin $(2.1 \pm 0.6$ versus $9.21 \pm 46, p=0.02)$. Synovial fluid osteoprotegerin was significantly higher than serum osteoprotegerin $(55.5 \pm 284$ versus $8.44 \pm 7 ; p=0.0001)$. Synovial fluid $\beta$-CrossLaps wasn't statistically different from serum levels $(6146 \pm 66818$ versus $6077 \pm 12212 ; p=0.5$ ). Ratios between synovial fluid and serum levels were 0.22 for osteocalcin, 6.57 for osteoprotegerin and 1.01 for $\beta$-CrossLaps.

Conclusions. Osteocalcin was higher in serum than in the synovial fluid. $\beta$-CrossLaps had similar values in serum and synovial fluid. Osteoprotegerin was higher in synovial fluid than serum.
\end{abstract}

Keywords: calcium pyrophosphate deposition disease, osteocalcin, osteoprotegerin, $\beta$-CrossLaps

\section{INTRODUCTION}

Calcium pyrophosphate deposition (CPPD) disease appears when calcium pyrophosphate crystals are deposited in hyaline cartilage, fibrocartilage and soft tissues. The gold standard for diagnosis of CPPD is fulfiling the McCarty criteria which include identification of calcium pyrophosphate crystals in synovial fluid analysis and typical radiographic calcifications $(1,2)$.

Measurement of bone markers is an important part of bone research. In the last years, the bone markers were studied in different types of arthritis (3-6). They can be useful to determine the bone dynamics, due to the fact that the bone is in continue remodelling. The use in clinical practice is difficult especially due to great endogenous, exogenous and technical variability of the markers. There are two main categories of bone markers, resorption and formation markers $(7,8)$. They can be measured from serum and synovial fluid.

The study of bone markers in serum and synovial fluid of CPPD patients could be useful from different points of view. First, due to the already known association with osteoarthritis. In osteoarthritis, bone markers could be modified due to generalized alteration of bone or locally, due to subchondral bone alteration characterized by increased bone turnover. Secondly, as a marker of joint degradation in CPPD $(5,9)$. 
The aim of the study was to measure synovial and serum levels of osteocalcin, osteoprotegerin and $\beta$-CrossLaps in patients with calcium pyrophosphate deposition disease.

\section{MATERIAL AND METHODS}

This pilot prospective study was performed in the Rheumatology Department, Emergency Clinical County Hospital, Cluj-Napoca. Patients fulfilling McCarty criteria for CPPD were consecutively included in the study. Polarized light microscopy was used for the synovial fluid analysis for calcium pyrophosphate crystal identification (10). Patients with inflammatory rheumatic diseases and the ones with a medication known to interfere with bone metabolism were excluded from the study. Also, patients with renal impairment were excluded.

Demographic data about age (years), gender, weight ( $\mathrm{kg}$ ), height (centimeters), clinical data about tender joint count (TJC), swollen joint count (SJC), visual analogue scale (VAS), type of arthritis (acute, chronic), type of articular involvement (monoarticular, oligoarticular, polyarticular), disease duration were collected in all patients. Also, laboratory analysis was done in all patients: erythrocyte sedimentation rate $(\mathrm{ESR}, \mathrm{mm} / \mathrm{h}), \mathrm{C}$ reactive protein $(\mathrm{CRP}, \mathrm{mg}$ / $\mathrm{dl})$, alkaline phosphatase (U/I), uric acid (mg/dl), total calcium $(\mathrm{mg} / \mathrm{dl})$, ionized calcium $(\mathrm{mg} / \mathrm{dl})$, magnesium $(\mathrm{mg} / \mathrm{dl})$ and iron $(\mu \mathrm{g} / \mathrm{dl})$.

The bone markers measured in the study were osteocalcin (OC, $\mathrm{ng} / \mathrm{ml})$, osteoprotegerin (OPG, pmol/ $\mathrm{ml})$ and beta-CrossLaps $(\beta \mathrm{CTx}, \mathrm{pg} / \mathrm{ml})$. They were measured in serum and in synovial fluid using ELISA kits (BioVendor LM, Czech Republic for osteocalcin, respectively osteoprotegerin and MyBiosource, USA for beta-CrossLaps) in accordance with the manufacturer's instructions. All measurements were performed on the same microplate reader (Tecan Sunrise, Switzerland). For OC the reference interval was $5-25 \mathrm{ng} / \mathrm{ml}$, for OPG the reference interval from unselected donors was $4.1 \pm 2.3 \mathrm{pmol} / \mathrm{l}$ and for $\beta$ CTx detection limit was $125-8,000 \mathrm{pg} / \mathrm{ml}$. The blood samples were collected from the antecubital vein, à jeun, between 8 and10 in the morning.

In all the patients were taken knee radiographs, which were graded for osteoarthritis according to Kellgren Lawrence (K/L) score (11). Osteoarthritis was defined in our study as a $\mathrm{K} / \mathrm{L}$ score $\geq 3$.
All patients included in the study signed the informed consent and the approval of the University Ethics Committee was obtained.

Statistical analysis was performed using Microsoft Excel. We considered a level of $\mathrm{p}<0.05$ statistically significant.

\section{RESULTS}

The study included eight patients who fulfilled McCarty criteria for CPPD. The characteristics of the study population are presented detailed in Table 1.

TABLE 1. General and clinical characteristics of study participants

\begin{tabular}{|l|c|}
\hline Variable & $\mathbf{n = 8}$ \\
\hline Age (years) & $64 \pm 9.6$ \\
\hline Gender ratio of male: female & $3: 5$ \\
\hline Weight $(\mathrm{kg})$ & $79.3 \pm 28$ \\
\hline Height (m) & $1.66 \pm 0.1$ \\
\hline BMI (kg/m²) & $28.1 \pm 6.13$ \\
\hline TJC & $2.8 \pm 2.1$ \\
\hline SJC & $1 \pm 0.75$ \\
\hline VAS & $7.3 \pm 0.9$ \\
\hline Acute arthritis & $7(87.5 \%)$ \\
\hline Chronic arthritis & $1(12.5 \%)$ \\
\hline Monoarticular disease & $1(12.5 \%)$ \\
\hline Oligoarticular disease & $1(12.5 \%)$ \\
\hline Polyarticular disease & $6(75 \%)$ \\
\hline Disease duration, weeks & $7.5 \pm 13$ \\
\hline
\end{tabular}

BMI - body mass index; TJC - tender joint count; SJC - swollen joint count; VAS-visual analogue scale;

The laboratory and radiographic characteristics are detailed in Table 2.

TABLE 2. Laboratory and radiographic characteristics of study participants

\begin{tabular}{|l|c|}
\hline Variable & $\mathbf{n = 8}$ \\
\hline ESR $(\mathrm{mm} / \mathrm{h})$ & $6.85 \pm 4.4$ \\
\hline CRP $(\mathrm{mg} / \mathrm{dl})$ & $0.7 \pm 0.9$ \\
\hline Creatinine $(\mathrm{mg} / \mathrm{dl})$ & $0.8 \pm 0.14$ \\
\hline Uric acid $(\mathrm{mg} / \mathrm{dl})$ & $3.66 \pm 0.64$ \\
\hline Alkaline phosphatase (U/l) & $102 \pm 56$ \\
\hline Ionic calcium (mg/dl) & $4.2 \pm 0.6$ \\
\hline Total calcium (mg/dl) & $9 \pm 1$ \\
\hline Magnesium (mg/dl) & $2.12 \pm 0.15$ \\
\hline Iron (microg/dl) & $82.81 \pm 15$ \\
\hline Mean K/L score & $2.78 \pm 0.1$ \\
\hline
\end{tabular}

ESR - erythrocyte sedimentation rate; CRP - C reactive protein; $\mathrm{K} / \mathrm{L}$-Kellgren/Lawrence score

Synovial fluid OC was significantly lower than serum OC ( $2.1 \pm 0.6$ versus $9.21 \pm 46, \mathrm{p}=0.02)$ in patients with CPPD (Table 3). 
Synovial fluid OPG was significantly higher than serum OPG (55.5 \pm 284 versus $8.44 \pm 7 ; \mathrm{p}=0.0001)$ (Table 3).

There was no significant difference between synovial fluid and serum $\beta C$ Tx levels $(6146 \pm 66818$ versus $6077 \pm 12212 ; \mathrm{p}=0.5$ ) (Table 3$)$.

TABLE 3. Comparison of serum and synovial levels of $O C, O P G$ and $\beta C T x$ in the study group

\begin{tabular}{|l|c|c|c|}
\hline Variable & Serum levels & Synovial fluid levels & $\mathbf{p}$ \\
\hline OC $(\mathrm{ng} / \mathrm{ml})$ & $9.21 \pm 46$ & $2.1 \pm 0.6$ & 0.02 \\
\hline OPG $(\mathrm{pmol} / \mathrm{ml})$ & $8.44 \pm 7$ & $55.5 \pm 284$ & 0.0001 \\
\hline$\beta C T x(\mathrm{pg} / \mathrm{ml})$ & $6077 \pm 12212$ & $6146 \pm 66818$ & 0.5 \\
\hline
\end{tabular}

OC-osteocalcin; OPG-osteoprotegerin; $\beta C T x-\beta$ CrossLaps;

Ratios between OC, OPG and $\beta$ CTx synovial fluid and serum levels were calculated. The highest ratio was obtained for OPG (6.57), followed by $\beta \mathrm{CTx}$ (1.01) and OC (0.22) (Fig. 1).

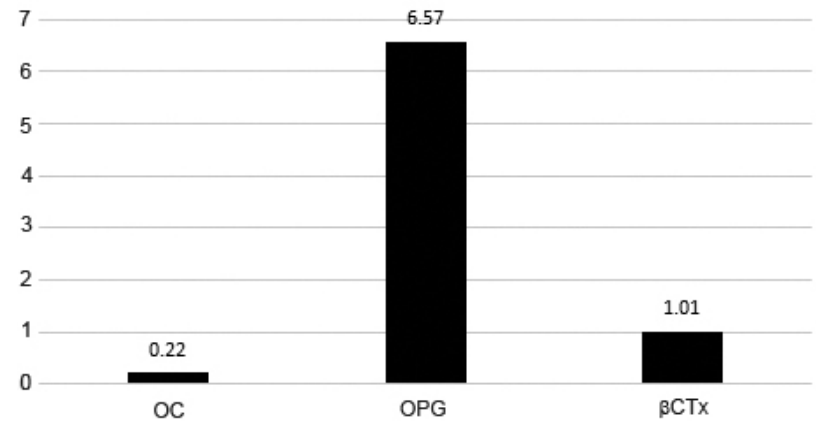

FIGURE 1. Ratios between synovial fluid and serum levels

Synovial fluid levels of bone markers were calculated according to the $\mathrm{K} / \mathrm{L}$ score for the severity of osteoarthritis. $\beta \mathrm{CTx}$ levels were significantly higher in patients with a $\mathrm{K} / \mathrm{L}$ score $<3$. Regarding $\mathrm{OC}$ and OPG levels there was not significantly different (Table 4).

TABLE 4. Synovial fluid levels of bone markers according to $K / L$ score

\begin{tabular}{|c|c|c|c|}
\hline Variable & $\begin{array}{c}\mathrm{K} / \mathbf{L}<\mathbf{3} \\
\mathbf{n}=\mathbf{3}\end{array}$ & $\begin{array}{c}\mathbf{K} / \mathbf{L} \geq \mathbf{3} \\
\mathbf{n}=\mathbf{5}\end{array}$ & P value \\
\hline OC & $2.1 \pm 0.18$ & $2.15 \pm 0.9$ & 0.4 \\
\hline OPG & $51.6 \pm 490$ & $57.97 \pm 233$ & 0.3 \\
\hline$\beta C T x$ & $6382 \pm 16244$ & $6004 \pm 41913$ & 0.009 \\
\hline
\end{tabular}

$\mathrm{K} / \mathrm{L}$-Kellgren/Lawrence score, $\mathrm{K} / \mathrm{L} \geq 3$-osteoarthritis

\section{DISCUSSION}

This study explores some of the bone turnover markers in serum and in synovial fluid of patients with CPPD disease. OC was measured as a bone for- mation marker, $\beta \mathrm{CTx}$ as a resorption marker and OPG as a regulator of bone metabolism. There aren't published data on OC, OPG and $\beta C T x$ in CPPD disease, except a study in which is detected serum and synovial fluid OC in a group of patients with inflammatory arthritis which include patients with chondrocalcinosis (3), crosslinked C-telopeptide fragments of type II collagen (CTX-II) in patients with pseudogout (12) and urinary cross laps in patients with chondrocalcinosis (13).

OC was studied in different types of arthritis like rheumatoid arthritis and osteoarthritis with contradictory results. Salisbury et al found that synovial fluid OC was lower in patients with osteoarthritis, rheumatoid arthritis and controls than serum osteocalcin (4). The authors suggest that synovial fluid OC may not be locally produced. In concordance with this, our study results found that serum OC was significantly higher than synovial fluid osteocalcin in patients with CPPD, similar to rheumatoid arthritis and osteoarthritis. Not in agreement with these results Garnero et al found serum osteocalcin and urinary Type I Collagen C-Telopeptide-Related Fraction ( CTX-I) lower in patients with knee osteoarthritis than the healthy controls (5).

In another study, serum and synovial levels of OC were determined in a group with inflammatory diseases including chondrocalcinosis, and in a group with mechanical joint effusion. Serum levels of OC were not different between the two groups, but in synovial fluid, the levels of OC were lower in the inflammatory group. The authors of the study suggest a periarticular osteoblastic depression in patients with arthritis (3).

In our study was detected $\beta C T x$ which is CTX-I. There was no significant difference between serum and synovial fluid values and the ratio between synovial fluid and serum levels of $\beta C T x$ was 1.01 . We found also higher levels of $\beta \mathrm{CTx}$ in patients with $\mathrm{K} / \mathrm{L}$ score $<3$. Lohmander et al found higher synovial fluid concentrations of CTX-II after injury, suggesting that CTX-II is released as an early event, leading in time to osteoarthritis (12).

Urinary CrossLaps were detected in a group of patients with chondrocalcinosis comparative with patients without the disease, but there was not a significant difference between the groups (13).

CTX-II was detected in synovial fluid of patients with pseudogout, injury and osteoarthritis comparative with healthy-knee volunteers. The levels of CTX-II were higher in all patients with joint disease 
or injury comparative with the controls, but the highest levels were in acute pyrophosphate crystal arthritis. Also, the ratio between CTX-II concentration in synovial fluid and serum was the highest (6.5). These results suggest a local production of CTX-II in patients with arthritis or injury (12). CTX-II is considered a biochemical marker of cartilage turnover, while CTX-I is useful as a marker of bone turnover (5).

In our study, significantly higher levels of OPG were found in synovial fluid, with the highest ratio between synovial fluid and serum levels (6.57). We also measured OPG in patients according to the $\mathrm{K} / \mathrm{L}$ score, but we did not find a significant difference.

OPG is an inhibitor of osteoclastogenesis, produced by osteoblasts, vascular smooth muscles, endothelial cells and also by the cartilage chondrocytes $(14,15)$. OPG could have an important role in CPPD due to the known fact that chondrocyte hypertrophy and proliferation is implicated in the pathogenesis of the disease. Also, Ramos et al identified a mutation in the gene TNFRSF11B, encoding OPG which causes osteoarthritis and chondrocalcinosis (16). More recently, Williams et al identified CCAL1 as TNFRSF11B and suggests the importance of studying OPG in CPPD patients (17).

From our knowledge, this is the first study to measure OPG in synovial fluid of patients with CPPD. OPG was studied in other types of arthritis. In a review, Schett et al (18) concluded that OPG block local bone erosion and systemic bone loss in patients with rheumatoid arthritis. These results are from animal models.

OPG was measured in serum and synovial fluid of patients with primary knee osteoarthritis was found higher in synovial fluid and also was associated with disease activity (19). Similar results were found by other authors too (20).

Salisbury et al suggest the ratio of synovial fluid/ serum of bone marker as a more accurate measurement of changes in the subchondral bone (4). In our study, synovial fluid/serum OPG ratio was the highest, followed by $\beta C T \mathrm{x}$ and osteocalcin.

The study has some limitation, particularly the small number of patients. For an exploration of the cartilage degradation in patients with CPPD disease could be more useful CTX-II rather than CTX-I. We also compared our results only with markers studied in other types of arthritis, not with markers from CPPD disease.

The results of this study provide a rationale for future studies of bone and cartilage degradation markers in serum and in synovial fluid of patients with CPPD.

\section{CONCLUSIONS}

In conclusion, bone formation marker, osteocalcin was higher in serum than in the synovial fluid. The bone resorption marker, $\beta C$ Tx had similar values in serum and synovial fluid. OPG was higher in synovial fluid than serum, with a significantly high synovial fluid/serum ratio.

\section{Acknowledgements}

This study was supported by a project of $\mathrm{PhD}$ research funded by Iuliu Hatieganu University of Medicine and Pharmacy Cluj-Napoca, No.7690/34/ 14.04.2016.

Conflict of interest: none declared

\section{REFERENCES}

1. McCarty DJ. Calcium pyrophosphate dihydrate crystal deposition disease. Arthritis Rheum. 1976;19(3 S):275-85.

2. Zhang W, Doherty M, Bardin T et al. European league against rheumatism recommendations for calcium pyrophosphate deposition. Part I: Terminology and diagnosis. Ann Rheum Dis. 2011;70(4):563-70.

3. Mattei JP, Ferrera V, Boutsen Y et al. Serum and synovial fluid osteocalcin in rheumatic diseases. Int J Clin Pharmacol Res. 1992;12(3):103-7.

4. Salisbury C, Sharif M. Relations between synovial fluid and serum concentrations of osteocalcin and other markers of joint tissue turnover in the knee joint compared with peripheral blood. Ann Rheum Dis. 1997; 56(9): 558-561.

5. Garnero P, Piperno M, Gineyts E et al. Cross sectional evaluation of biochemical markers of bone, cartilage, and synovial tissue metabolism in patients with knee osteoarthritis: Relations with disease

activity and joint damage. Ann Rheum Dis. 2001; 60: 619-626.

6. Ben Achour W, Bouaziz M, Mechri M et al. A cross sectional study of bone and cartilage biomarkers: Correlation with structural damage in rheumatoid arthritis. Libyan J Med. 2018; 13(1):1512330.

7. Hlaing TT, Compston JE. Biochemical markers of bone turnover uses and limitations. Ann Clin Biochem. 2014; 51:189-202.

8. Shetty S, Kapoor N, Bondu JD et al. Bone turnover markers: Emerging tool in the management of osteoporosis. Indian J Endocrinol Metab. 2016;20(6):846-52.

9. Bailey AJ, Mansell JP, Sims TJ et al. Biochemical and mechanical properties of subchondral bone in osteoarthritis. Biorheology. 2004;41(3-4):349-58.

10. Swan A, Amer H, Dieppe P. The value of synovial fluid assays in the diagnosis of joint disease: a literature survey. Ann Rheum Dis. 2002; 61(6):493-8. 
11. Kellgren J, Lawrence J. Radiological assessment of osteoarthritis. Ann Rheum Dis. 1957;16(4):494.

12. Lohmander LS, Atley LM, Pietka TA et al. The Release of Crosslinked Peptides From Type II Collagen Into Human Synovial Fluid Is Increased Soon After Joint Injury and in Osteoarthritis. Arthritis Rheum. 2003; 48(11)3130-3139.

13. Ramonda R, Musacchio E, Perissinotto E et al. Prevalence of chondrocalcinosis in Italian subjects from northeastern Italy. The Pro.V.A. (PROgetto Veneto Anziani) Study. Clin Exp Rheumatol. 2009;27(6):981-4.

14. Bucay N, Sarosi I, Dunstan CR et al. Osteoprotegerin-deficient mice develop early onset osteoporosis and arterial calcification. Genes Dev. 1998;12(9):1260-8.

15. Wang B, Jin H, Shu B et al. Chondrocytes-specific expression of osteoprotegerin modulates osteoclast formation in metaphyseal bone. Sci Rep. 2015; 5: 13667.

16. Ramos YFM, Bos SD, Van Der Breggen R et al. A gain of function mutation in TNFRSF11B encoding osteoprotegerin causes osteoarthritis with chondrocalcinosis. Ann Rheum Dis. 2015;74(9):1756-62.

17. Williams CJ, Qazi U, Bernstein M et al. Mutations in osteoprotegerin account for the CCAL1 locus in calcium pyrophosphate deposition disease. Osteoarthr Cartil. 2018; 26(6):797-806.

18. Schett G., Redlich K., Smolen J.S. The role of osteoprotegerin in arthritis. Arthritis Res Ther. 2003; 5:239.

19. Pilichou A, Papassotiriou I, Michalakakou K et al. High levels of synovial fluid osteoprotegerin (OPG) and increased serum ratio of receptor activator of nuclear factor-KB ligand (RANKL) to OPG correlate with disease severity in patients with primary knee osteoarthritis. Clin Biochem. 2008; 41 (9):746-9.

20. Csifo $\mathrm{E}$, Katona $\mathrm{T}$, Arseni $\mathrm{J}$ et al. Correlation of Serum and Synovial Osteocalcin, Osteoprotegerin and Tumor Necrosis Factor-Alpha with the Disease Severity Score in Knee Osteoarthritis. Acta Medica Marisiensis. 2014;60(3):102-5. 